\title{
Object-based inhibition of return in static displays
}

\author{
HEATHER JORDAN and STEVEN P. TIPPER \\ University of Wales, Bangor, Gwynedd, Wales
}

\begin{abstract}
After attention has been oriented to a location, inhibition mechanisms prevent the return of attention shortly afterward. This inhibition can be associated with an object in such a way that after cuing attention to the object, inhibition can move with the object to a new location. Recent research has noted that the object-based inhibition of return effect in moving displays is much smaller than the effect observed in static displays, and hence may be of little functional utility. However, we demonstrate that, on the contrary, the large effects observed in static displays are produced precisely because of the existence of object-based frames, which can be additive with location-based frames of reference.
\end{abstract}

Many visual environments are highly complex, and hence attention systems have evolved to select particular perceptual inputs to guide action. One of the main problems to be solved when organisms interact with complex environments is how objects relevant to behavior are found. Therefore, efficient mechanisms of visual search are crucial. One of the main features of an efficient search system is that it be able to move to novel locations until a relevant object is discovered. That is, attention must not repeatedly return to recently examined loci since target stimuli may never be found. The importance of this point can easily be appreciated when considering an animal foraging for food.

Posner and Cohen (1984) discovered a mechanism that would facilitate such efficient search. They showed that after attention had been automatically oriented to a spatial location via a peripheral onset cue, processing of stimuli at the cued location was impaired. They argued that this impairment reflected an inhibitory mechanism preventing the return of attention to the previously attended location. Posner and Cohen called this mechanism inhibition of return (IOR) and said that its function was to facilitate search of novel loci.

IOR has now been observed in a wide range of tasks. It is obtained when subjects detect the onset of targets with either keypress or saccades (see, e.g., Abrams \& Dobkin, 1994), when they identify colors (see, e.g., Lupiáñez, Milán, Tornay, Madrid, \& Tudela, 1997), letters (Lupiáñez, Milliken, Solano, Weaver, \& Tipper, 1998), or auditory frequency (Mondor, Breau, \& Milliken, 1998); and in cross-modal studies, in which the cue is presented in the visual modality and the target is presented in the auditory modality (Reuter-Lorenz, Jha, \& Rosenquist, 1996). Of most pertinence to the aims of this article, the frames of reference that mediate IOR have also been investigated.

It has been demonstrated (e.g., Maylor, 1985; Posner \& Cohen, 1984) that IOR is based on environmental rather than retinal coordinates. Thus, when eye movements were

This research has been supported by BBSRC Grant S06761 to S.P.T. Correspondence should be addressed to S. P. Tipper, School of Psychology, University of Wales, Bangor, Gwynedd, Wales LL57 2DG (e-mail: pss060@bangor.ac.uk). made between the cue offset and target onset, inhibition was associated with a location on the computer screen where the cue had appeared rather than a location on the retina that was stimulated by the cue. However, Tipper, Driver, and Weaver (1991) noted that although such a frame of reference was adequate for searching for nonmobile objects in static scenes, mammals appeared to be able to search for moving objects among other moving objects. In the latter situation, inhibition of only environmental loci may not be sufficient. When an object examined by attention moved to a new locus, it would no longer be inhibited, and hence attention may needlessly reexamine this object. However, if inhibition were also object based, so that it moved with the object, then search in such environments would be far more efficient.

Tipper et al. (1991) demonstrated object-based IOR with the following procedure adapted from Posner and Cohen (1984). After cuing, the two boxes rotated $90^{\circ}$ around the computer screen. After such a rotation, both cued and uncued boxes were equally distant from the cued location. If IOR is object based, detection of the target should be impaired in the cued relative to the uncued box. In a series of experiments, such object-based IOR was demonstrated and has since been confirmed and extended in numerous other studies (e.g., Abrams \& Dobkin, 1994; Gibson \& Egeth, 1994; Tipper, Jordan, \& Weaver, in press; Tipper \& Weaver, in press; Tipper, Weaver, Jerreat, \& Burak, 1994; Weaver, Lupiáñez, \& Watson, 1998).

However, a recent study by Müller and von Mühlenen (1996) has questioned the generality of object-based IOR. Although they reported replicating object-based IOR when using techniques based on those of Tipper and Weaver (in press) and Weaver et al. (1998), they were not able to produce significant effects using their techniques. There could be many reasons why the effect is not observed in all situations, and these are of course important boundary conditions that will reveal properties of the system. However, Müller and von Mühlenen's main criticism was that relative to the traditional techniques used to demonstrate IOR, in which static displays are cued, the object-based effect seemed to be more fragile, being much smaller and fading with practice. 

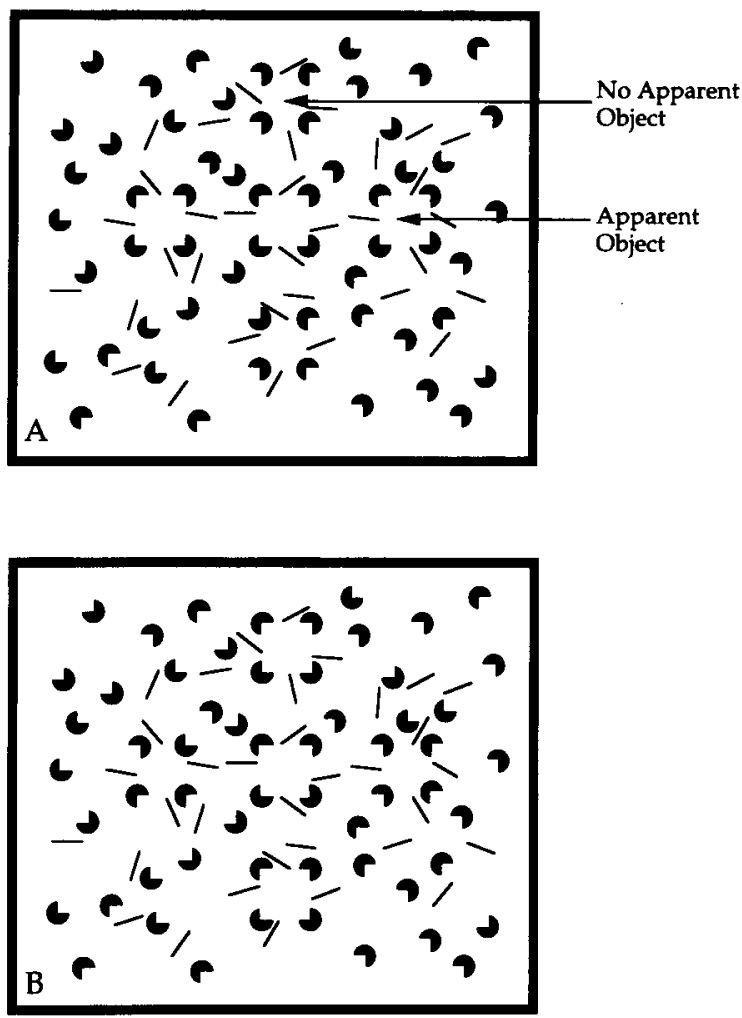

Figure 1. Experimental displays showing apparent objects (Kanizsa squares) on the horizontal (panel $A$ ) and vertical (panel B) axes. See text for details (drawn to scale).

As noted by Weaver et al. (1998), the fact that IOR fades with practice is hardly surprising when one considers the technique used to produce the effect. In exogenous cuing tasks, the cue is nonpredictive of target location; subjects are told it is irrelevant to their task and hence it should be ignored. There is a massive literature describing habituation processes (see Peeke \& Petrinovich, 1984, for review), in which organisms no longer respond to stimuli that are irrelevant to their behavioral goals. Such habituation to peripheral cues is almost certain to take place, and hence a reduction in attentional orienting will result in dramatically smaller IOR effects. Weaver et al. went on to show that the decline in IOR with practice did not distinguish between the effects in moving or static displays, since all effects declined.

Of more relevance here is the observation that objectbased IOR associated with moving objects is smaller than that associated with the location cued in static scenes. Müller and von Mühlenen (1996) suggested from the evidence for more robust effects with static displays that IOR is mediated only by location-based frames, and object-based frames serve little function. However, the aim of this article is to demonstrate the opposite conclusion. Note that in the traditional static display procedures, outline boxes are cued, and thus we argue that IOR effects are robust in static displays precisely because of the existence of object-based frames. That is, Tipper et al. (1994) have demonstrated that in fact two frames of reference exist: Inhibition can be associated with a location initially cued and with an object that has moved to a new location. Both these location- and object-based effects are smaller than those for displays containing static objects.

Therefore, the IOR effects observed in traditional procedures, in which static peripheral boxes are cued and in which targets are presented in those boxes, has in fact never been a simple measure of pure location-based effects. This procedure necessarily results in both locationand object-based frames being additive and hence produces very robust effects. Indeed, in studies in which an empty environmental locus is cued and attention is not oriented to a cued object, the size of the effect is quite small. For example, in Wright and Richards's (1996) procedure, in which the spatial locations were not marked by visible peripheral boxes, only $15 \mathrm{msec}$ of IOR was observed in the procedure most similar to that reported here. This compares with the more typical 40- to 50-msec effect observed when peripheral boxes act as place holders (see, e.g., Posner \& Cohen, 1984).

Our approach in confirming this conclusion was to use methodologies that are different from those used thus far, but that converge with those previous methods. That is, evidence for location- and object-based effects has been observed only with moving objects. As noted, the generality of these effects has been questioned. Therefore, the experiments described here investigated object-based IOR in static displays in which objects never move.

The logic behind these experiments was to present essentially the same stimulation to the retina, but in one situation apparent objects (Kanizsa squares) were visible, whereas in the other no apparent objects (identical "Kanizsa inducers" misoriented) were visible in the same physical location (see Davis \& Driver, 1997). With this technique, we could observe whether inhibition was larger when a visible object had been cued than when only a location had been cued. This result is predicted if both object- and location-based frames are additive. Figure 1 shows examples of the displays that we used. They contain features that when oriented in one way produce contourless apparent objects (i.e., Kanisza squares). However, when these features are reoriented, no such squares are visible, and hence only a spatial location is cued.

\section{METHOD}

\section{Subjects}

Fourteen undergraduates of the psychology department at the University of Wales, Bangor, participated in this study for course credit (or payment). The mean age of the subjects was 21.5 years (range 18-35 years). All subjects reported normal or corrected-to-normal acuity and were naive to the purpose of the experiment.

\section{Apparatus}

The study was conducted in a darkened room. The subjects were seated at a table $70 \mathrm{~cm}$ in front of a 14-in. color VGA monitor (refresh rate $70 \mathrm{~Hz}$ ) with their heads resting on a chinrest. The computer monitor was adjusted so that they were looking directly at the center of the screen. The study was carried out on a 486/33 IBM-compatible PC. and stimulus presentation and response recording were controlled by MEL 1.0
} 
(Schneider, 1988) software. Responses were collected using the buttons on an analogue joystick that was interfaced with the computer through a game port.

A black cardboard collar was fitted around the monitor so that an area $19 \times 19 \mathrm{~cm}$ of the monitor was visible. The collar was $9 \mathrm{~cm}$ deep, which was sufficient to obscure the plastic surround on the monitor.

\section{Stimuli}

The stimuli consisted of black "pacmen" and lines on a gray background (Figure 1). The horizontal and vertical extent of the display was $18 \times 18 \mathrm{~cm}$ (subtending $14^{\circ} \times 14^{\circ}$ of visual angle when viewed $70 \mathrm{~cm}$ from the monitor). The pacmen were made up by drawing black circles $1 \mathrm{~cm}$ in diameter and then overlaying one quarter of each circle with a gray $0.5 \times 0.5 \mathrm{~cm}$ square. The black lines were $1.5 \mathrm{~cm}$ in length and 1 pixel in width.

Three apparent (illusory) squares (i.e., Kanizsa squares) that subtended $2^{\circ}$ of visual angle appeared when the inducer pacmen were appropriately oriented. One of the apparent objects (Kanizsa square) always appeared in the center of the display. The other squares flanked it either on the horizontal (Figure 1, panel A) or vertical (Figure 1, panel B) axis. The remainder of the pacmen and lines were distributed across the display and oriented to prevent inadvertent apparent figure completion. The position and orientation of the filler stimuli remained constant across all trials.

It was found necessary to present filler items because the four pacmen features that were misaligned to prevent the perception of a Kanizsa square could still be grouped together via the use of proximity. Such figure-ground grouping gave the misaligned pacmen the status of features belonging to an object. The presentation of the filler features prevented this proximity grouping and hence provided a purer measure of location-based cuing.

The target consisted of a $1.0 \times 1.0 \mathrm{~cm}$ filled white square. The cues were differentiated by appearing as white hollow outline boxes subtending $1.5 \times 1.5 \mathrm{~cm}$ with a line width of 5 pixels.

\section{Procedure}

The target appeared with equal probability in the peripheral apparent squares (Kanizsa squares) and the empty locations (misaligned inducers), equal distances above, below, left, and right of the central square. The target was presented on $80 \%$ of the trials and the remaining $20 \%$ of trials were catch trials requiring no response. The subjects were furthe told that luminance changes (white outline squares) prior to the target were distractors and to be ignored. The initial luminance change appeared in one of the four peripheral loci (peripheral cue), and the second appeared in the central location (central cue) before the onset of the target.

The display was described to the subjects, who were told that "gray squares" would appear shortly after the beginning of the trial. There was no reference to the "Kanizsa illusion." They were told that the three squares could appear on either the horizontal or the vertical axis and that this would vary randomly from trial to trial. The subjects were instructed that they were to perform a target detection task and that the target would appear above, below, left, or right of the center of the display with equal probability. At the end of the practice trials, all subjects reported observing the three apparent objects (Kanizsa squares).

The subjects initiated each trial by pressing the space bar. At the start of each trial, black circles and lines appeared on a light gray background (Figure 2A). After 1,120 msec, the display was overwritten so that one quarter of each circle was removed, resulting in the appearance of pacmen (Figure 2B). In half the trials, the apparent objects (Kanizsa squares) appeared on the horizontal axis (Figure 1, panel A), whereas no object appeared on the vertical meridian due to misaligned inducers. In the remaining $50 \%$ of trials, the vertical meridian was occupied by the Kanizsa squares, and the horizontal meridian was occupied by the misaligned inducers (Figure 1, panel B). After 1,120 msec, the (peripheral) cue was presented for $83 \mathrm{msec}$ (Figure $2 \mathrm{C}$ ) and then overwritten, followed after $500 \mathrm{msec}$ by a cue in the central square (central cue) for $83 \mathrm{msec}$ (Figure 2D). After a delay of $520 \mathrm{msec}$, the target appeared equiprobably in one of the four locations for $83 \mathrm{msec}$ (Figure 2E) and was overwritten. The stimulus onset asynchrony (SOA) from the cue to the target was $1,186 \mathrm{msec}$
The subjects were instructed to respond as rapidly as possible without making anticipatory errors. The trial was terminated if no response was made within $1,000 \mathrm{msec}$ of the onset of the target. Failure to respond within this period resulted in a feedback signal. This consisted of a $500-\mathrm{Hz}$ computer-generated tone for $500 \mathrm{msec}$. Responding to a catch trial resulted in the same feedback. Each subject completed 20 practice trials before commencement of the experimental trials. There were three rest breaks during the experimental trials, one after every 120 trials. The subjects were debriefed at the conclusion of the experiment, which lasted approximately $40 \mathrm{~min}$.

\section{Design}

Two orthogonal variables were manipulated within subjects - cuing (with two levels: cued, uncued) and type of stimuli in which the target appeared (with two levels: apparent object present, apparent object absent). The apparent object (Kanizsa square) appeared on the horizontal or vertical axis with equal probability, varying trial by trial. There were 100 trials in the apparent-object-absent (location-IOR) condition, 50 of which were cued trials. There were 100 trials in the apparent-objectpresent (object- and location-IOR) conditions, 50 of which were cued. Two hundred filler trials were presented in which the cue appeared in a region marked with a Kanizsa square and the target appeared in an unmarked region or vice versa. Although these trials were not analyzed, they were included to ensure that cue location did not predict target location. The remaining $20 \%$ of trials consisted of catch trials in which no target appeared

\section{RESULTS}

Trials with an incorrect response or a response time (RT) less than 100 or longer than $1,000 \mathrm{msec}$ were excluded as error trials. The mean median RTs for each condition are shown in Table 1. The median RTs of each condition for each subject were analyzed using a $2 \times 2$ (cuing $\times$ type of stimuli) analysis of variance (ANOVA). There was a main effect of cuing [cued vs. uncued; $F(1,13)$ $=34.5, p<.001]$ due to longer $\mathrm{RT}$ s to cued regions. This is consistent with the IOR effect. The interaction between type of stimuli (apparent object present vs. apparent object absent) and cuing was also significant $[F(1,13)=$ $21.2, p<.001]$. A larger IOR effect $(42 \mathrm{msec})$ was observed when an apparent object occupied the cued region than when no apparent object was visible (18-msec IOR). There was no main effect of stimulus type.

The mean error rate for each condition is shown in Table 1 . A $2 \times 2$ repeated measures ANOVA was carried out on the percentage errors for each condition. There were no significant main effects or interactions for cuing or type of stimuli. The mean error rate for catch trials was $0.89 \%$.

Clearly, the results of this experiment indicate a larger IOR effect when the cued region is occupied by an apparent object (Kanizsa square). However, it is possible that the larger cuing effect was an artifact of perceptual detection of the cue and/or target stimuli within the object, rather than greater inhibition associated with the apparent object. There are three ways in which this might be the case. First, Reuter-Lorenz et al. (1996) examined the effect of target detectability (via luminance intensity) on the IOR effect. They showed that targets that were harder to detect, with associated longer RTs, produced larger IOR effects. Therefore, it is essential to confirm that the larger IOR effect when an object is cued is not due to 


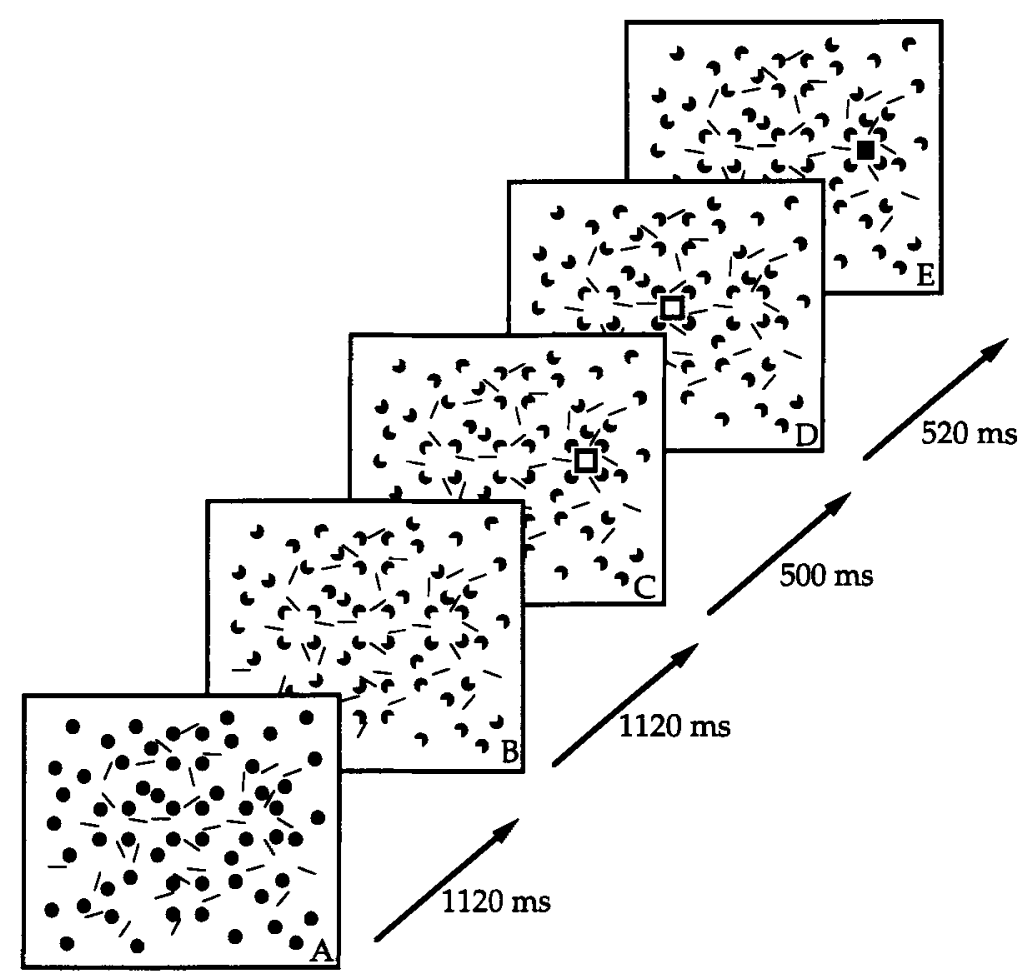

Figure 2. Sequence of displays used in this experiment. The condition illustrated is that of cued apparent object where the peripheral cue and target appear in a locus marked by a Kanizsa square. The timing refers to the onset of each display; duration of the peripheral cue $(C)$, central cue (D), and target $(E)$ was $83 \mathrm{msec}$ in each case. The cues and target, which are shown as black in this figure, were in fact white against a light-gray background. See text for further details.

harder target detection. Observations of RT to detect targets in the baseline uncued conditions show that this possible confound cannot explain our data. That is, there is a trend for target detection to be faster when it is presented within an object. Therefore, if anything, we are underestimating the size of IOR in cued objects.

The second way in which target detection performance might influence the interpretation of the cuing effect is as follows: Because target detection in the uncued condition of the object-present condition was faster than that of the object-absent condition, the larger IOR in the presence of an object could be produced by the combination of slower cued trials and faster uncued trials. To confirm that the larger IOR in the object-present condition was not caused by the faster uncued trials, we reanalyzed the data but used the data from the uncued object-absent condition in both the object-present and object-absent analyses. The interaction between display type and cuing was still significant $[F(1,13)=10.8, p<.05]$. Therefore, the finding of a greater IOR when an object is cued was not due to faster RTs to uncued targets when appearing within an object.

Third, and finally, it was necessary, of course, to undertake a further control experiment to ensure that cue detection was not facilitated by the presence of an apparent object. That is, if the cue was more salient when presented within an object, this may have evoked greater inhibitory feedback (see, e.g., Houghton \& Tipper, 1994). Fourteen undergraduate psychology students were presented with the first three displays (Figure 2, panels A-C) and asked to detect the onset of the outline white square (previously the cue) that could appear above, below, left, or right of the center of the display. The target appeared in each location with equal probability, and the remaining $20 \%$ of trials were catch trials in which no target appeared. Therefore, in half the trials the target appeared in an apparent object (Kanizsa square). All the subjects completed 20 practice trials and 116 experimental trials. The mean median RT for targets appearing in regions where an apparent object was visible was $315 \mathrm{msec}(S D=42 \mathrm{msec})$, compared with those where an apparent object was not visible, the mean median RT of which was $317 \mathrm{msec}(S D=44 \mathrm{msec})$. A two-tailed $t$ test indicated that there was no significant difference between the mean response latencies to stimuli appearing in regions occupied by apparent objects over those where no apparent objects were visible $[t(13)=-.06$, n.s. $]$.

\section{DISCUSSION}

It has been previously noted that IOR can be associated with both a moving object and the location to which attention was oriented (e.g.. 
Table 1

The Mean Median Response Times (RTs) for Correct Trials and Mean Error Rate in Percentage (PE)

\begin{tabular}{|c|c|c|c|c|c|c|c|}
\hline \multicolumn{8}{|c|}{ Condition } \\
\hline \multicolumn{2}{|c|}{$\begin{array}{c}\text { Cued } \\
\text { Apparent } \\
\text { Object }\end{array}$} & \multicolumn{2}{|c|}{$\begin{array}{c}\text { Uncued } \\
\text { Apparent } \\
\text { Object }\end{array}$} & \multicolumn{2}{|c|}{$\begin{array}{l}\text { Cued No } \\
\text { Apparent } \\
\text { Object }\end{array}$} & \multicolumn{2}{|c|}{$\begin{array}{c}\text { Uncued No } \\
\text { Apparent } \\
\text { Object }\end{array}$} \\
\hline RT & $\mathrm{PE}$ & RT & $\mathrm{PE}$ & RT & $\mathrm{PE}$ & RT & $\mathrm{PE}$ \\
\hline 298.5 & 2.7 & 255.9 & 2.4 & 287.3 & 2.4 & 269.2 & 2.1 \\
\hline
\end{tabular}

Tipper et al., 1994). The separate location- and object-based IOR ef fects were significantly smaller than those observed when static objects were cued. We predicted, therefore, that the latter static effects were the product of both location- and object-based frames. The results of the present experiment clearly confirm this conclusion. Even though the physical properties of the displays were essentially the same, IOR when an object was cued was significantly larger than when only a location was cued. This effect appears to be robust; unpublished data show the contrast between object present versus object absent to be still present after four testing sessions over 2 days

As noted, the notion that IOR can be observed in two frames of reference has previously been demonstrated by Tipper et al. (1994) and Weaver et al. (1998), but it has been important to confirm this with converging methodologies that do not employ moving displays. The present findings support other work showing that exogenous orienting of attention can also be both location and object based (Egly, Driver, \& Rafal, 1994), as well as the substantial literature arguing for object-based frames in attention (e.g., Baylis \& Driver, 1992; Duncan, 1984; Kahneman \& Treisman, 1984; Kramer \& Jacobson, 1991).

Furthermore, evidence that attention can gain access to multiple frames of reference has been demonstrated in clinical populations. For example, patients with visual neglect, usually associated with right parietal lesions, tend to be impaired in responding to stimuli presented to the left side of space. Like the literature pertaining to IOR, this neglect has been considered to be mediated by spatial representations. However, a series of studies has now demonstrated that neglect can also be object based. For example, Behrmann and Tipper (1994; see also Tipper \& Behrmann, 1996) have shown that neglect can rotate with the left side of an object from the left to the right side of space (see also Caramazza \& Hillis, 1990; Driver \& Halligan, 1991). Of most relevance here, Behrmann and Tipper (1998) have shown that with appropriate techniques, neglect can appear in two frames of reference at once (see also Humphreys \& Riddoch, 1994, 1995, Riddoch \& Humphreys, 1994 for similar findings). The coexistence of both location- and objectbased neglect provides powerful converging evidence for the notion that mechanisms of attention can gain access to multiple frames of reference.

In conclusion, the present results, combined with those from other studies (Abrams \& Dobkin, 1994; Gibson \& Egeth, 1994; Tipper et al., in press; Tipper et al., 1991; Tipper et al., 1994; Weaver et al., 1998) confirm that object-based IOR can be observed in a variety of circumstances. It is not the case that the small size of the effect when objects move, relative to when they remain stable, suggests that object-based IOR has limited utility. Ironically, the large effects when cued objects remain static is produced because of the existence of object-based frames, which are additive with location-based frames.

\section{REFERENCES}

Abrams, R. A., \& Dobkin, R. S. (1994). Inhibition of return: Effects of attentional cuing on eye movement latencies. Journal of Experimental Psychology: Human Perception \& Performance, 20, 467-477.

BaYlis, G. C., \& DRIVER, J. (1992). Visual parsing and response competition: The effect of grouping factors. Perception \& Psychophysics, 51, 145-162.

BEHRMANN, M., \& TipPER, S. P. (1994). Object-based attentional mechanisms: Evidence from patients with unilateral neglect. In C. Umiltà
\& M. Moscovitch (Eds.), Attention and performance XIV: Conscious and unconscious processing and cognitive functioning (pp. 351-375). Hillsdale, NJ: Erlbaum.

BehrmanN, M., \& TiPper, S. P. (1998). Attention accesses multiple reference frames: Evidence from neglect. Manuscript submitted for publication.

Caramazza, A., \& Hillis, A. E. (1990). Where do semantic errors come from? Cortex, 26, 95-122.

DAVIS, G., \& DRIVER, J. (1997). Spreading of visual attention across modally- versus amodally-completed regions. Psychological Science, 8, 275-281.

Driver, J., \& Halligan, P. W. (1991). Can visual neglect operate in object-centered co-ordinates? An affirmative single-case study. Cognitive Neuropsychology, 8, 475-496.

DUNCAN, J. (1984). Selective attention and the organization of visual information. Journal of Experimental Psychology: General, 113, 501-517.

EGLY, R., DRIVER, J., \& RAFAL, R. D. (1994). Shifting visual attention between objects and locations: Evidence from normal and parietal lesion subjects. Journal of Experimental Psychology: General, 123, 161-177.

GIBSON, B. S., \& EGETH, H. (1994). Inhibition of return to object-based and environment-based locations. Perception \& Psychophysics, 55, 323-339.

Houghton, G., \& TIPPER, S. P. (1994). A model of inhibitory mechanisms in selective attention. In D. Dagenback and T. Carr (Eds.), Inhibitory mechanisms of attention, memory and language (pp. 53-112). Orlando, FL: Academic Press.

HUMPHREYS, G. M., \& RIDDOCH, M. J. (1994). Attention to within-object and between-object spatial representations: Multiple sites for visual selection. Cognitive Neuropsychology, 11, 207-241.

HumphreYs, G. M., \& RidDOCH, M. J. (1995). Separate coding of space within and between perceptual objects: Evidence from unilateral visual neglect. Cognitive Neuropsychology, 12, 283-311.

Kahneman, D., \& Treisman, A. M. (1984). Changing views of attention and automaticity. In R. Parasuraman \& D. Davies (Eds.), Varieties of attention (pp. 29-61). Orlando, FL: Academic Press.

KRAMER, A. F., \& JACOBSON, A. (1991). Perceptual organization and focused attention: The role of objects and proximity in visual processing. Perception \& Psychophysics, 50, 267-284.

Lupiáñez, J., Milán, E. G., Tornay, F. J., Madrid, E., \& Tudela, P. (1997). Does IOR occur in discrimination tasks? Yes, it does, but later. Perception \& Psychophysics, 59, 1241-1254.

Lupiáñez, J., Milliken, B., Solano, C., Weaver, B., \& Tipper, S. P. (1998). On the endogenous control over the time course of inhibition of return. Manuscript submitted for publication.

MAYLOR, E. A. (1985). Facilitatory and inhibitory components of orienting in visual space. In M. I. Posner \& O. S. M. Marin (Eds.), Attention and performance XI (pp. 189-204). Hillsdale, NJ: Erlbaum.

Mondor, T. A., BreaU, L. M., \& Milliken, B. (1998). Inhibitory processes in auditory selective attention: Evidence of location-based and frequency-based inhibition of return. Perception \& Psychophysics, 60, 296-302.

Müller, H. J., \& VON Mühlenen, A. (1996). Attentional tracking and inhibition of return in dynamic displays. Perception \& Psychophysics, $58,224-249$.

Peeke, H. V. S., \& Petrinovich, L. (1984). Habituation, sensitization, and behavior. New York: Academic Press.

POSNER, M. I., \& COHEN, Y. A. (1984). Components of visual orienting. In H. Bouma \& D. G. Bouwhuis (Eds.), Attention and performance $X$ (pp. 531-556). Hillsdale, NJ: Erlbaum.

Reuter-LorenZ, P. A., JhA, A. P., \& Rosenquist, J. N. (1996). What is inhibited in inhibition of return? Journal of Experimental Psychology: Human Perception \& Performance, 22, 367-378.

RIDDOCH, M. J., \& HUMPHREYS, G. W. (1994). Towards an understanding of neglect. In M. J. Riddoch \& G. W. Humphreys (Eds.), Cognitive neuropsychology and cognitive rehabilitation (pp. 125-149). Hove, U.K.: Erlbaum.

SCHNEIDER, W. (1988). Micro Experimental Laboratory: An integrated system for IBM PC compatibles. Behavior Research Methods, Instruments, \& Computers, 20, 206-217. 
TipPer, S. P., \& Behrmann, M. (1996). Object-centered not scene-based visual neglect. Journal of Experimental Psychology: Human Perception \& Performance, 22, 1261-1278.

TIPPER, S. P., DRIVER, J., \& WEAVER, B. (1991). Object-centered inhibition of return of visual attention. Quarterly Journal of Experimental Psychology, 43A, 289-298.

Tipper, S. P., Jordan, H., \& Weaver, B. (in press). Scene-based and object-centered inhibition of return: Evidence for dual orienting mechanisms. Perception \& Psychophysics.

TIPPER, S. P., \& WEAVER, B. (in press). The medium of attention: Locationbased, object-centred, or scene-based? In R. Wright (Ed.), Visual attention. New York: Oxford University Press.

Tipper, S. P., Weaver, B., Jerreat, L. M., \& Burak, A. L. (1994)
Object-based and environment-based inhibition of return of visual attention. Journal of Experimental Psychology: Human Perception \& Performance, 20, 478-499.

WEAVER, B., LuPIÁÑEZ, J., \& WATSON, F. L. (1998). The effects of practice on object-based, location-based, and static-display inhibition of return. Perception \& Psychophysics, 60, 993-1003.

WRIGHT, R. D., \& RiCHARDS, C. M. (1996). Inhibition of return at multiple locations in visual space. Canadian Journal of Experimental Psychology, 50, 324-327.

(Manuscript received June 30, 1997; revision accepted for publication January $20,1998$. ) 